\title{
A cluster randomized controlled Trial to Evaluate an Ambulatory primary care Management program for patients with dyslipidemia: the TEAM study
}

\author{
Julie Villeneuve PhD, Jacques Genest MD, Lucie Blais PhD, Marie-Claude Vanier MSc, \\ Diane Lamarre MSc, Marc Fredette PhD, Marie-Thérèse Lussier MD, Sylvie Perreault PhD, \\ Eveline Hudon MD, Djamal Berbiche PhD, Lyne Lalonde PhD
}

Previously published at www.cmaj.ca

\section{ABSTRACT}

Background: Few studies have reported the efficacy of collaborative care involving family physicians and community pharmacists for patients with dyslipidemia.

Methods: We randomly assigned clusters consisting of at least two physicians and at least four pharmacists to provide collaborative care or usual care. Under the collaborative care model, pharmacists counselled patients about their medications, requested laboratory tests, monitored the effectiveness and safety of medications and patients' adherence to therapy, and adjusted medication dosages. After 12 months of follow-up, we assessed changes in lowdensity lipoprotein (LDL) cholesterol (the primary outcome), the proportion of patients reaching their target lipid levels and changes in other risk factors.

Results: Fifteen clusters representing a total of 77 physicians and 108 pharmacists were initially recruited, and a total of 51 physicians and 49 pharmacists were included in the final analyses. The collaborative care teams followed a total of 108 patients, and the usual care teams followed a total of 117 patients. At baseline, mean LDL cholesterol level was higher in the collaborative care group (3.5 v. 3.2 $\mathrm{mmol} / \mathrm{L}, p=0.05$ ). During the study, patients in the collaborative care group were less likely to receive high-potency statins $(11 \%$ v. $40 \%)$, had more visits with health care professionals and more laboratory tests, were more likely to have their lipid-lowering treatment changed and were more likely to report lifestyle changes. At 12 months, the crude incremental mean reduction in LDL cholesterol in the collaborative care group was $-0.2 \mathrm{mmol} / \mathrm{L}$ ( $95 \%$ confidence interval $[\mathrm{Cl}]-0.3$ to -0.1$)$, and the adjusted reduction was $-0.05(95 \% \mathrm{Cl}-0.3$ to 0.2$)$. The crude relative risk of achieving lipid targets for patients in the collaborative care group was $1.10(95 \% \mathrm{Cl} 0.95$ to 1.26$)$, and the adjusted relative risk was $1.16(95 \% \mathrm{Cl} 1.01$ to 1.34$)$.

Interpretation: Collaborative care involving physicians and pharmacists had no significant clinical impact on lipid control in patients with dyslipidemia. International Standard Randomized Controlled Trial register no. ISRCTN66345533.

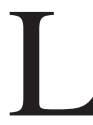
ipid-lowering pharmacotherapy reduces morbidity and mortality caused by cardiovascular disease. ${ }^{1}$ However, the management of dyslipidemia is not always optimal. ${ }^{2,3}$ In two Canadian studies, ${ }^{4,5}$ low-density lipoprotein (LDL) cholesterol goals were attained by $62 \%-64 \%$ of highrisk patients and $79 \%-82 \%$ of moderate-risk patients.

Worldwide, the role of community pharmacists is expanding. ${ }^{6}$ In Quebec, pharmacists may initiate and adjust drug therapy in accordance with a physician's prescription and may request laboratory analyses when needed. In the United States, more than 40 states have similar collaborative practice regulations.

In this study, we compared a collaborative model involving physicians and pharmacists with usual care for patients with dyslipidemia. The primary outcome was the change in LDL cholesterol level, and the secondary outcomes were the proportion of patients achieving their target lipid levels and changes in other risk factors for cardiovascular disease after 12 months of follow-up.

\section{Methods}

\section{Design}

We conducted an open cluster randomized controlled trial from May 2005 to January 2008. We recruited clusters of physicians and pharmacists and randomly assigned the clusters to provide collaborative care or usual care. We subsequently recruited patients, each of whom was followed for 12

From the Faculties of Pharmacy (Villeneuve, Blais, Vanier, Lamarre, Perreault, Lalonde) and of Medicine (Lussier, Hudon), Université de Montréal, Montréal, Que.; the Research Team in Primary Care (Villeneuve, Vanier, Lussier, Hudon, Berbiche, Lalonde) and Hôpital de la Cité-de-la-Santé (Vanier), Centre de santé et de services sociaux de Laval, Laval, Que.; SanofiAventis Canada Inc. (Villeneuve), Laval, Que.; the Department of Cardiology (Genest), McGill University Health Centre, Royal Victoria Hospital, Montréal, Que.; Ordre des pharmaciens du Québec (Lamarre), Montréal, Que.; and the Department of Management Sciences (Fredette), École des hautes études commerciales de Montréal, Montréal, Que.

CMAJ 2010. DOI:10.1503/cmaj.090533 
months. Clinicians received $\$ 50$ per patient recruited, and pharmacists in the collaborative care group received \$104 per patient to apply the intervention. The study was approved by the ethics review boards of all three institutions. The health care professionals and patients provided written consent.

\section{Participants}

We recruited clusters of health care professionals from May to October 2005. We defined a cluster as participating physicians from one or two medical clinics located in close geographic proximity and pharmacists working in community pharmacies located within $5 \mathrm{~km}$ of these clinics. Initially, a cluster had to include at least five physicians and at least two pharmacies with a minimum of two parmacists per pharmacy. In August 2005, to speed up recruitment, the minimum number of physicians per cluster was reduced to two.

We recruited patients from January 2006 to January 2007, using the following inclusion criteria: age at least 18 years; able to speak and read French or English; a patient at a participating pharmacy in the same cluster as the patient's physician or having no usual pharmacy; and a candidate (on the basis of laboratory results within the previous three months) for initiation of 3-hydroxy-3-methyl-glutaryl-coenzyme A reductase inhibitor (statin) monotherapy or already receiving statin monotherapy with inadequate control, where inadequate control was defined ${ }^{8}$ as LDL cholesterol $2.5 \mathrm{mmol} / \mathrm{L}$ or higher and ratio of total cholesterol to highdensity lipoprotein (HDL) cholesterol 4.0 or higher for highrisk patients (10-year risk for coronary artery disease $\geq 20 \%)$ or LDL cholesterol $3.5 \mathrm{mmol} / \mathrm{L}$ or higher and ratio of total cholesterol to HDL cholesterol 5.0 or higher for moderaterisk patients (10-year risk for coronary artery disease $11 \%$ $19 \%$ ). We excluded patients who were taking more than one lipid-lowering medication, those who had experienced an acute cardiovascular event in the previous six months, those who were unlikely to complete the study because of lifethreatening disease or poor health, those with triglyceride level greater than $5.0 \mathrm{mmol} / \mathrm{L}$, those with $\mathrm{LDL}$ cholesterol greater than $5.0 \mathrm{mmol} / \mathrm{L}$, those with any contraindication to statin treatment and those who had participated in another clinical trial within the past two months.

\section{Randomization}

We randomly assigned the clusters of health care professionals to provide collaborative care or usual care. We stratified the randomization by type of medical clinic (conventional, family medicine group or combined conventional and family medicine group) and number of physicians per cluster (up to three or more than three). We also blocked the clusters, with two or four clusters per block and balanced randomization within each block (1:1 ratio of collaborative care v. usual care).

\section{Collaborative care by physicians and pharmacists}

Collaborative care is a multifaceted intervention replicating the key characteristics of a cohesive health care team.9.10

The intervention was detailed in a treatment protocol and was supported by clinical and communication tools. ${ }^{10,11}$ The physicians were responsible for prescribing statin therapy. On a prescription form, the physician specified the patient's risk factors for cardiovascular disease, the results of the patient's most recent lipid testing, the prescribed treatment (the particular statin, initial and maximum doses, titration schedule and target lipid levels) and recommended lifestyle changes. The target lipid levels were as recommended in the 2003 Canadian guidelines ${ }^{8}$ or individualized targets, at the physician's discretion.

During the patient's initial visit to the pharmacy (which lasted 30 minutes), the pharmacist provided counselling and used a patient decision aid ${ }^{12}$ to draw up a treatment plan, which included lifestyle changes and pharmacotherapy. The pharmacist then scheduled so-called titration visits (lasting 15 minutes each) at two-month intervals. During the titration visits, the pharmacist evaluated lifestyle changes, the patient's tolerance of and adherence with the pharmacotherapy, and the drug's efficacy and then adjusted the statin dosage accordingly. If necessary, the pharmacist scheduled an adherence visit (lasting 30 minutes) to discuss strategies to optimize treatment. When target lipid levels were achieved, the pharmacist scheduled a follow-up visit (15 minutes) for three months later. After each visit, the pharmacist prepared an interim report and sent it to the physician by fax. The intervention ended when any one of the following milestones occurred: target lipid levels were reached at the follow-up visit, the patient had not achieved target lipid levels at the maximum statin dosage prescribed, the patient experienced severe intolerance to the drug or the patient asked to end the intervention. The costs of statin treatment and laboratory tests were not covered by the research grant.

In November 2005, the pharmacists in the collaborative care group attended a one-day training workshop..$^{13}$ During this workshop, we used formal lectures, role-playing and interactive exercises to present the Canadian treatment recommendations, ${ }^{8}$ guidance about the pharmacotherapy, information about the treatment protocol and communication strategies for optimizing adherence.

In December 2005, the pharmacists and physicians within each cluster were invited to a two-hour gathering to meet each other and to discuss the intervention.

\section{Usual care}

Physicians in the usual care group requested laboratory tests and adjusted lipid-lowering pharmacotherapy. Pharmacists dispensed medications and provided usual counselling. The pharmacists in the usual care group did not receive any training specific to the study, and they did not meet the physicians in their cluster.

\section{Outcome measures}

Patients attended evaluation visits at baseline and at 12 months. At baseline, a research nurse documented the patient's medical history. At each of these two visits, the nurse drew 12-hour fasting blood samples for measurement of blood glucose and serum lipid levels. Laboratory personnel at the Cité-de-la-Santé Hospital, Laval, Quebec, performed the analyses, and we estimated LDL cholesterol levels using the Friedwald equation. The research nurse also measured the patient's height, weight and waist circumference and took 


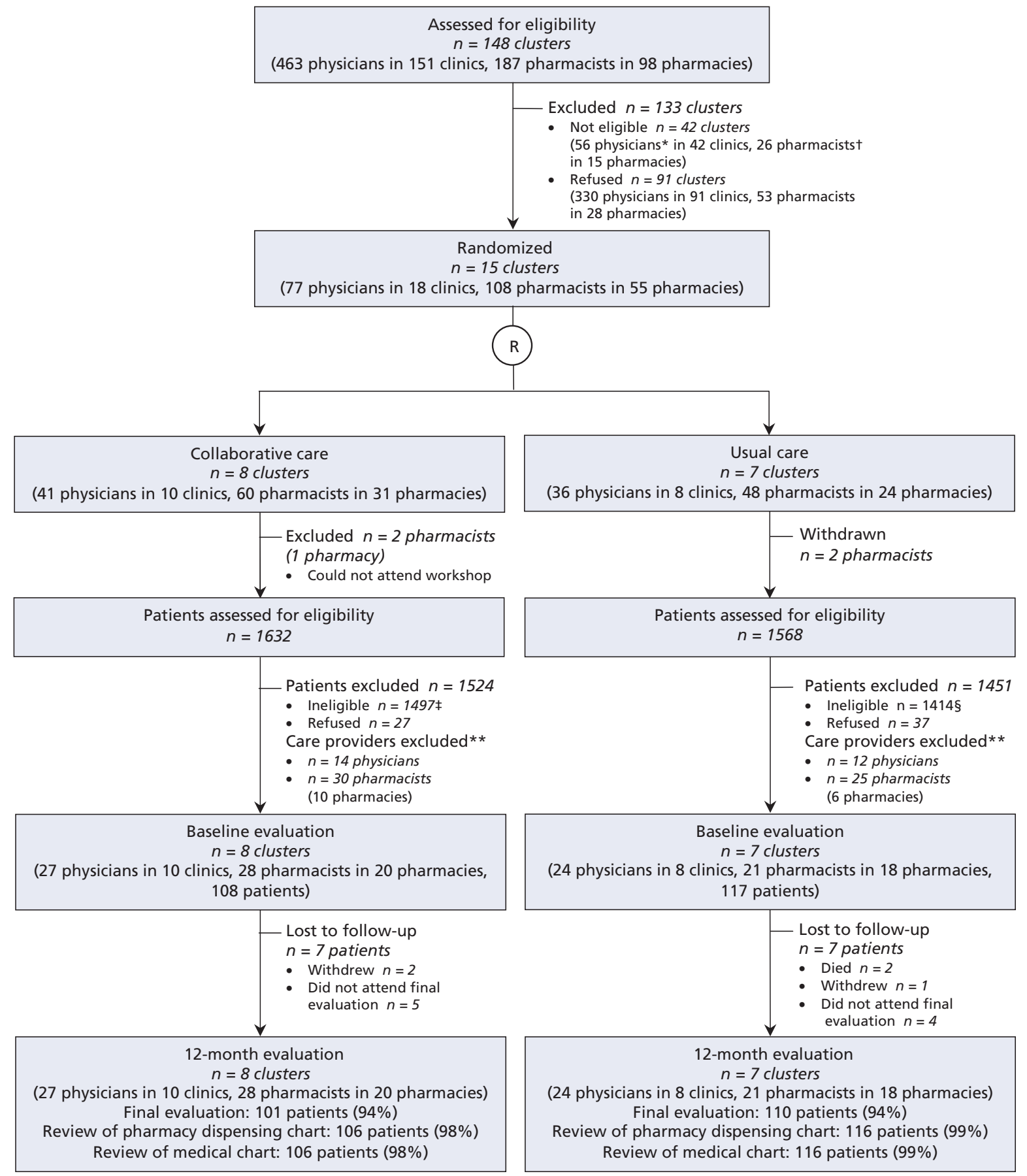

Figure 1: Flow chart for cluster randomized controlled trial comparing collaborative care by physicians and pharmacists with usual care for patients with dyslipidemia. $\mathrm{R}$ = randomization. *Physicians excluded because fewer than five physicians in their respective clusters agreed to participate $(n=56)$. tPharmacists excluded because fewer than two pharmacists in their respective pharmacies agreed to participate ( $n$ $=16$ ) or because they could not attend the workshop $(n=10)$. \#First exclusion criteria: low risk of coronary artery disease $(n=1160)$, not a candidate to initiate or modify statin monotherapy $(n=310)$, triglycerides $>5.0 \mathrm{mmol} / \mathrm{L}$ or low-density-lipoprotein cholesterol $>5.0$ $\mathrm{mmol} / \mathrm{L}(n=4)$, life-threatening disease $(n=13)$, taking more than one lipid-lowering drug $(n=3)$, contraindication to statin therapy $(n=$ 1), acute cardiovascular event in past six months $(n=5)$, participation in another trial within past two months $(n=1)$. §First exclusion criteria: low risk of coronary artery disease $(n=992)$, not a candidate to initiate or modify statin monotherapy $(n=371)$, triglycerides $>5.0$ $\mathrm{mmol} / \mathrm{L}$ or low-density-lipoprotein cholesterol $>5.0 \mathrm{mmol} / \mathrm{L}(n=14)$, life-threatening disease $(n=16)$, taking more than one lipid-lowering drug $(n=10)$, contraindication to statin therapy $(n=3)$, acute cardiovascular event in past six months $(n=4)$, participation in another trial within past two months $n=4)$. **Care providers excluded because they were not involved in follow-up for any study patients. 
Table 1: Baseline characteristics of clusters of health care professionals and patients

\begin{tabular}{|c|c|c|}
\hline \multirow[b]{2}{*}{ Characteristic } & \multicolumn{2}{|c|}{ Study group; no. (\%)* } \\
\hline & Collaborative care & Usual care \\
\hline \multicolumn{3}{|l|}{ Medical clinics } \\
\hline Number & $10(100)$ & $8(100)$ \\
\hline \multicolumn{3}{|l|}{ Conventional clinic } \\
\hline$\leq 3$ physicians & $2(20)$ & $1(12)$ \\
\hline$>3$ physicians & $1(10)$ & $1(12)$ \\
\hline Family medicine group & $5(50)$ & $4(50)$ \\
\hline $\begin{array}{l}\text { Conventional and family medicine group } \\
\text { (combined) }\end{array}$ & $2(20)$ & $2(25)$ \\
\hline \multicolumn{3}{|l|}{ Physicians } \\
\hline Number & $27(100)$ & $24(100)$ \\
\hline Sex, women & $15(56)$ & $10 \quad(42)$ \\
\hline \multicolumn{3}{|l|}{ Graduation year } \\
\hline Up to 1990 & $21(78)$ & $14(58)$ \\
\hline $1991-2000$ & $4(15)$ & $7(29)$ \\
\hline After 2001 & $2 \quad(7)$ & $3(12)$ \\
\hline Time worked, h/wk, mean (SD) & $38.8(8.8)$ & $36.6(10.3)$ \\
\hline Attended a conference on dyslipidemia since 2003 & 25 (93) & $24(100)$ \\
\hline \multicolumn{3}{|l|}{ Pharmacies } \\
\hline Number & $20(100)$ & $18(100)$ \\
\hline Pharmacist-hours per week, mean (SD) & $112.7(35.4)$ & $109.6(53.5)$ \\
\hline $\begin{array}{l}\text { Hourly no. of prescriptions per pharmacist, } \\
\text { mean (SD) }\end{array}$ & $19.5(7.7)$ & $18.8(9.6) \dagger$ \\
\hline \multicolumn{3}{|l|}{ Pharmacists } \\
\hline Number & $28(100)$ & $21(100)$ \\
\hline Sex, women & $24(86)$ & $12(57)$ \\
\hline \multicolumn{3}{|l|}{ Graduation year } \\
\hline Up to 1990 & $8(29)$ & $5(24)$ \\
\hline $1991-2000$ & 11 (39) & $12(57)$ \\
\hline After 2001 & $9(32)$ & $4(19)$ \\
\hline Time worked, h/wk, mean (SD) & $37.2(7.6) \ddagger$ & $35.6(15.7) \S$ \\
\hline Attended a conference on dyslipidemia since 2003 & $20(71)$ & $11(52)$ \\
\hline \multicolumn{3}{|l|}{ Patients } \\
\hline Number & $108(100)$ & $117(100)$ \\
\hline Patients per cluster, median (range) & $13(1-25)$ & $16(10-25)$ \\
\hline Age, yr, mean (SD) & $59.3(9.6)$ & $62.2(12.0)$ \\
\hline Sex, men & $69(64)$ & $70 \quad(60)$ \\
\hline \multicolumn{3}{|l|}{ Risk category for coronary artery disease } \\
\hline Moderate & 28 (26) & $20(17)$ \\
\hline High & $80(74)$ & $97(83)$ \\
\hline New user of a statin & $92(85)$ & $85(73)$ \\
\hline Previous cardiovascular event & 21 (19) & $21(18)$ \\
\hline Diabetes mellitus & $43(40)$ & $54(46)$ \\
\hline Hypertension & $72(67)$ & 71 (61) \\
\hline Current smoker & 38 (35) & $24(21)$ \\
\hline Family history of early cardiovascular disease & $26(24)$ & $33(28)$ \\
\hline
\end{tabular}

Note: SD = standard deviation

*Unless indicated otherwise.

tData missing for one pharmacy.

¥Data missing for eight pharmacists.

§Data missing for five pharmacists. three blood pressure readings after the patient had been seated for at least five minutes. We calculated and recorded the mean of the second and third readings. At the 12-month evaluation, the patient completed a self-administered questionnaire to document lifestyle changes and adverse events.

We used the Framingham equation ${ }^{8}$ to estimate the patient's 10-year risk of coronary artery disease. We used the following target levels: LDL cholesterol less than $3.5 \mathrm{mmol} / \mathrm{L}$ and ratio of total cholesterol to HDL cholesterol less than 5.0 for patients at moderate risk for coronary artery disease and LDL cholesterol less than $2.5 \mathrm{mmol} / \mathrm{L}$ and ratio of total cholesterol to HDL cholesterol less than 4.0 for patients at high risk for coronary artery disease.

We reviewed the patients' medical charts and the pharmacists' log books to document visits to clinicians and laboratory tests. We reviewed the pharmacies' dispensing charts to document patients' receipt of lipid-lowering pharmacotherapy.

\section{Statistical analyses}

We categorized statins associated with an expected reduction in LDL cholesterol of less than $45 \%$ as having low potency (atorvastatin $\leq 20 \mathrm{mg}$, fluvastatin $\leq 80 \mathrm{mg}$, lovastatin $\leq 80 \mathrm{mg}$, pravastatin $\leq 80 \mathrm{mg}$ and simvastatin $\leq 40 \mathrm{mg}$, where all values represent daily doses) and those with an expected reduction in LDL cholesterol of $45 \%$ or more as having high potency (atorvastatin $>20 \mathrm{mg}$, rosuvastatin $\geq 5 \mathrm{mg}$ and simvastatin $>40 \mathrm{mg}){ }^{14-16}$ For each patient, we computed treatment gaps for LDL cholesterol and the ratio of total cholesterol to HDL cholesterol as the baseline value minus the target level, as defined by treatment guidelines. ${ }^{8}$

In accordance with the intention-totreat principle, we estimated missing clinical data at the patient level, using the last-value-carried-forward approach (i.e., last results available in the medical chart or the baseline value). For all lipid values, the mean time (standard deviation [SD]) of the last value carried forward was 139 (109) days after the baseline evaluation in the collaborative care group and 150 (117) days after the baseline evaluation in the usual care group.

To compare mean changes in LDL cholesterol (defined as value at 12 
months minus baseline value) and other risk factors, with adjustment for baseline characteristics of patients and clusters of health care professionals, we developed multivariable linear regression models taking into account the withincluster correlation. We included in the multivariable models those variables deemed significant $(p<0.2)$ in a bivariable model including treatment group. We then applied a backward selection procedure and included in the final model those variables that were statistically significant at $p<0.1$.

We computed the proportion of patients in each group who were at or below their target lipid levels at 12 months. We estimated relative risks (RR) and $95 \%$ confidence intervals $(95 \% \mathrm{CI})$, with the usual care group as the reference group, using generalized linear models, taking into account the within-cluster correlation, with a log link and robust sandwich variance estimator using a modified Poisson regression. ${ }^{17}$ The final multivariable models were defined as described previously.

As planned in the study protocol, we stratified the analyses by risk for coronary artery disease, treatment status and type of medical clinic.

We compared lipid-lowering treatment and use of health care services between the two groups using univariable linear regression or modified Poisson regression models, taking the within-cluster correlation into account.

We computed the proportion of days during the follow-up period with coverage by the medication dispensed. ${ }^{2,18}$ The denominator was the number of days between baseline and the date of the 12-month evaluation (or the date of death). For patients taking more than one lipid-lowering medication and those for whom a new medication was dispensed during the period covered by a previous prescription, we counted the overlapping number of days of available therapy just once. We deemed as "adherent" those patients for whom the amount of medication dispensed covered at least $80 \%$ of the number of days during the follow-up period. We deemed therapy to be "persistent" if a lipid-lowering medication was dispensed for the patient within 60 days before the 12-month evaluation. Using a dispensing interval of 45 days did not change the results.

We calculated that with 14 clusters and 16 patients per cluster, the study would have statistical power of $80 \%$ to detect a mean difference between groups of $0.5 \mathrm{mmol} / \mathrm{L}$ (SD $0.75 \mathrm{mmol} / \mathrm{L}$ ) in the change in LDL cholesterol from baseline to 12 months, with a two-sided $t$ test and a type 1 error of 5\%. We assumed a within-cluster correlation coefficient of 0.08 and a dropout rate of $15 \%$.

\section{Results}

Of 148 clusters of health care professionals approached to participate in this study, 15 clusters, with a total of 51 phys-

Table 2: Baseline values and changes in serum lipid levels, blood pressure, blood glucose, body weight, body mass index and waist circumference from baseline to month 12

\begin{tabular}{|c|c|c|c|c|c|c|c|c|c|c|c|c|}
\hline \multirow[b]{2}{*}{ Variable } & \multicolumn{4}{|c|}{$\begin{array}{c}\text { Group; baseline value, } \\
\text { mean (SD) }\end{array}$} & \multicolumn{8}{|c|}{ Group; change from baseline to month 12 , mean $(95 \% \mathrm{Cl})$} \\
\hline & Coll & $\begin{array}{l}\text { aborative } \\
\text { care }\end{array}$ & & $\begin{array}{l}\text { Usual } \\
\text { care }\end{array}$ & & $\begin{array}{l}\text { Collaborative } \\
\text { care* }\end{array}$ & & $\begin{array}{l}\text { Usual } \\
\text { caret }\end{array}$ & & $\begin{array}{c}\text { Crude } \\
\text { difference }\end{array}$ & & $\begin{array}{l}\text { Adjusted } \\
\text { difference }\end{array}$ \\
\hline \multicolumn{13}{|l|}{$\begin{array}{l}\text { Serum lipid levels, } \\
\mathrm{mmol} / \mathrm{L}\end{array}$} \\
\hline LDL cholesterol & 3.5 & $(0.9) \ddagger$ & 3.2 & $(0.8)$ & -1.1 & $(-1.3$ to -1.0$)$ & -0.9 & $(-1.0$ to -0.8$)$ & -0.2 & $(-0.3$ to -0.1$)$ & -0.05 & $5(-0.3$ to 0.2$) \S$ \\
\hline $\begin{array}{l}\text { Ratio total to HDL } \\
\text { cholesterol }\end{array}$ & 4.4 & $(1.0)$ & 4.3 & $(1.2)$ & -0.9 & $(-1.0$ to -0.7$)$ & -0.7 & $(-0.8$ to -0.5$)$ & -0.2 & $(-0.4$ to 0.03$)$ & -0.1 & $(-0.3$ to 0.03$) \neq \neq$ \\
\hline Triglycerides & 1.9 & $(0.8)$ & 1.9 & $(0.8)$ & -0.3 & $(-0.4$ to -0.1$)$ & -0.3 & $(-0.4$ to -0.2$)$ & 0.02 & $2(-0.2$ to 0.2$)$ & -0.03 & $3(-0.2$ to 0.1$) \S \S$ \\
\hline \multicolumn{13}{|l|}{ Blood pressure, $\mathrm{mm} \mathrm{Hg}$} \\
\hline Systolic & 125.7 & (14.2) & 125.3 & (12.5) & 1.2 & $(-2.9$ to 5.3$)$ & 2.5 & $(-1.4$ to 6.4$)$ & -1.3 & $(-6.4$ to 3.8$)$ & -1.3 & $(-6.4$ to 3.8$)$ \\
\hline Waist circumference, $\mathrm{cm}$ & 100.9 & (14.1) & 100.4 & (14.8) & 1.2 & $(-0.8$ to 3.2$)$ & 2.8 & (0.7 to 5.0$)$ & -1.6 & $(-4.2$ to 1.0$)$ & -1.6 & $(-4.3$ to 1.0$) \ddagger \ddagger \ddagger$ \\
\hline
\end{tabular}

Note: $\mathrm{Cl}=$ confidence interval, $\mathrm{HDL}=$ high-density lipoprotein, $\mathrm{LDL}=$ low-density lipoprotein.

*Missing data at month 12: serum lipid levels $(n=8)$, blood pressure $(n=10)$, fasting blood glucose $(n=9)$, body mass index $(n=9)$, waist circumference $(n=9)$.

tMissing data at month 12: serum lipid levels $(n=8)$, blood pressure $(n=9)$, fasting blood glucose $(n=9)$, body mass index $(n=8)$, waist circumference $(n=9)$.

$\neq p=0.05$ compared with usual care group after accounting for correlation within clusters.

$\S$ Adjusted for use of statin and LDL cholesterol at baseline (analysis for all patients).

$* * p=0.01$ compared with usual care group after accounting for correlation within clusters.

††Adjusted for total cholesterol and use of statin at baseline (analysis for all patients).

$\ddagger \ddagger$ Adjusted for risk of coronary artery disease and use of statin at baseline.

$\S \S A d j u s t e d$ for patient's age and hourly number of prescriptions per pharmacist.

$* * *$ Data missing for two patients.

t††Adjusted for sex of patient and pharmacist's years of experience.

$\ddagger \ddagger \ddagger$ Adjusted for sex of patient and of physician. 
icians and 49 pharmacists, were eligible and agreed to participate. These clusters were involved in the follow-up for a total of 225 patients (Figure 1). Two hundred and eleven (94\%) of the patients attended the 12-month evaluation, and risk factors for cardiovascular disease were determined for 209 of these.

The health care professionals in the collaborative care and usual care groups were similar (Table 1). Compared with the usual care group, women constituted a greater proportion of physicians (56\% v. $42 \%)$ and pharmacists (86\% v. $57 \%)$ in the collaborative care group. The majority of the patients were men, and most were at high risk for coronary artery disease (Table 1). Patients in the collaborative care group were younger (59.3 v. 62.2 years), were more likely to be new users of a statin (85\% v. $73 \%)$ and were more likely to be smokers (35\% v. $21 \%)$.

\section{LDL cholesterol and other cardiovascular risk factors}

At baseline, patients in the collaborative care group had higher LDL cholesterol ( 3.5 v. $3.2 \mathrm{mmol} / \mathrm{L}, p=0.05)$ and total cholesterol (5.7 v. $5.4 \mathrm{mmol} / \mathrm{L}, p=0.01)$ (Table 2). At 12 months, patients in the collaborative care group had an additional reduction of $0.2 \mathrm{mmol} / \mathrm{L}$ in LDL cholesterol $(95 \%$ CI -0.3 to -0.1 ) relative to patients in the usual care group. However, the adjusted difference was not statistically significant $(-0.05 \mathrm{mmol} / \mathrm{L}, 95 \% \mathrm{CI}-0.3$ to 0.2$)$.

At 12 months, the changes in other risk factors for cardiovascular disease did not differ between the two groups.

\section{Target levels}

At 12 months, 87 (81\%) of the patients in the collaborative care group and $86(74 \%)$ of those in the usual care group had reached their target lipid levels (crude RR 1.10, 95\% CI 0.95 to 1.26 ), as defined by the 2003 Canadian guidelines. ${ }^{8}$ After adjustment for baseline LDL cholesterol, patients in the collaborative care group were significantly more likely to reach their targets (RR 1.16, 95\% CI 1.01 to 1.34).

Shortly before the end of the recruitment phase, new lipid targets were defined by the 2006 Canadian guidelines, ${ }^{19}$ which recommended a target LDL cholesterol level less than 2.0 $\mathrm{mmol} / \mathrm{L}$ for patients at high risk for coronary artery disease. The proportion of high-risk patients who had reached this target at 12 months was 49\% (39/80) in the collaborative care group and $43 \%$ (42/97) in the usual care group (adjusted RR 1.2, 95\% CI 0.9 to 1.7 ). For patients in the collaborative care group, the physician had to specify the lipid targets on the prescription form. On the basis of this information, 21 patients in the collaborative care group who were at high risk for coronary artery disease had targets prescribed as defined in the 2006 guidelines, and $17(81 \%)$ of them had reached their target at 12 months.

\section{Stratified analyses}

When the analysis was stratified by risk for coronary artery disease, treatment status and type of medical clinic within the clusters, there was no incremental reduction in LDL cholesterol for patients in the collaborative care group (Table 3). Patients in the collaborative care group who were at high risk

Table 3: Change in low-density lipoprotein (LDL) cholesterol and proportion of patients reaching their lipid target* at 12 months, by risk of coronary artery disease, treatment status and type of medical clinic within clusters

\begin{tabular}{|c|c|c|c|c|c|}
\hline \multirow[b]{2}{*}{ Category } & \multicolumn{3}{|c|}{$\begin{array}{c}\text { Change in LDL cholesterol (mmol/L), between-group } \\
\text { difference, mean }(95 \% \mathrm{Cl})\end{array}$} & \multicolumn{2}{|c|}{$\begin{array}{l}\text { Proportion of patients reaching target, } \\
\qquad \mathrm{RR}(95 \% \mathrm{Cl})\end{array}$} \\
\hline & Crude & & Adjusted & Crude & Adjusted \\
\hline \multicolumn{6}{|l|}{$\begin{array}{l}\text { Risk of coronary artery } \\
\text { disease }\end{array}$} \\
\hline Moderate $(n=48)$ & $-0.14(-0.84$ to 0.56$)$ & 0.14 & $(-0.52$ to 0.79$) \dagger$ & 0.87 (0.69 to 1.11$)$ & $0.96(0.76$ to 1.20$) \neq$ \\
\hline \multicolumn{6}{|l|}{ Treatment status } \\
\hline $\begin{array}{l}\text { Initiating lipid-lowering } \\
\text { therapy }(n=177)\end{array}$ & $-0.12(-0.34$ to 0.10$)$ & -0.004 & $4(-0.24$ to 0.23$) \ddagger$ & 1.08 (0.93 to 1.27$)$ & $1.14(0.98$ to 1.32$) \neq$ \\
\hline $\begin{array}{l}\text { Already receiving lipid- } \\
\text { lowering therapy }(n=48)\end{array}$ & $-0.33(-0.76$ to 0.11$)$ & -0.22 & $(-0.65$ to 0.21$) \ddagger$ & 1.09 (0.76 to 1.57$)$ & $1.18(0.84$ to 1.66$) \neq$ \\
\hline \multicolumn{6}{|l|}{$\begin{array}{l}\text { Type of medical clinic } \\
\text { within cluster }\end{array}$} \\
\hline $\begin{array}{l}\text { Conventional and family } \\
\text { medicine group (combined) } \\
(n=34)\end{array}$ & $-0.41(-1.01$ to 0.19$)$ & -0.34 & $(-0.83$ to 0.14$) \dagger$ & 1.58 (0.98 to 2.54$)$ & $1.59(1.00$ to 2.52$) \neq$ \\
\hline
\end{tabular}

Note: $\mathrm{Cl}=$ confidence interval, $\mathrm{HDL}=$ high-density lipoprotein, $\mathrm{LDL}=$ low-density lipoprotein.

*Definition of targets: for patients with moderate risk of coronary artery disease, LDL cholesterol $<3.5 \mathrm{mmol} / \mathrm{L}$ and ratio of total to $\mathrm{HDL}$ cholesterol $<5.0$; for patients with high risk for coronary artery disease, LDL cholesterol $<2.5 \mathrm{mmol} / \mathrm{L}$ and ratio of total to $\mathrm{HDL}$ cholesterol $<4.0$.

†Adjusted for use of statins and baseline LDL cholesterol.

¥Adjusted for baseline LDL cholesterol. 
of coronary artery disease were more likely to reach the target lipid levels of the 2003 guidelines $^{8}$ (adjusted RR 1.22, 95\% CI 1.04 to 1.43 ), whereas the proportions reaching target lipid levels were similar among patients at moderate risk (adjusted RR $0.96,95 \%$ CI 0.76 to 1.20 ).

\section{Lipid-lowering therapy and use of health care services}

Patients in the collaborative care group were less likely to have a prescription for a high-potency statin at baseline (RR $0.28,95 \%$ CI 0.16 to 0.50 ) and were more likely to remain on a lowpotency statin at 12 months (RR $1.61,95 \%$ CI 1.23 to 2.12 ) (Table 4). More patients in the collaborative care group had had a change in their lipid-lowering treatment during the study (RR $1.70,95 \%$ CI 1.05 to 2.75$)$. Most patients had lipid-lowering medication dispensed within 60 days before the 12-month visit (representing persistent therapy; 93 [86\%] of patients receiving collaborative care and 95 [81\%] of patients receiving usual care), and most had sufficient medication to cover at least $80 \%$ of the follow-up period (representing adherence $\geq 80 \% ; 78$ [72\%] of patients receiving collaborative care and 79 [68\%] receiving usual care). As noted above, analysis for a dispensing interval of 45 days did not change the results. More patients receiving collaborative care reported having discussed lifestyle changes with their pharmacist and implementing such changes.

During the 12-month follow-up, the mean number of visits to a physician did not differ between groups. However, patients receiving collaborative care had fewer laboratory tests requested by physicians. On average, patients receiving

Table 4: Description of lipid-lowering therapy and use of health care services during the 12-month follow-up period

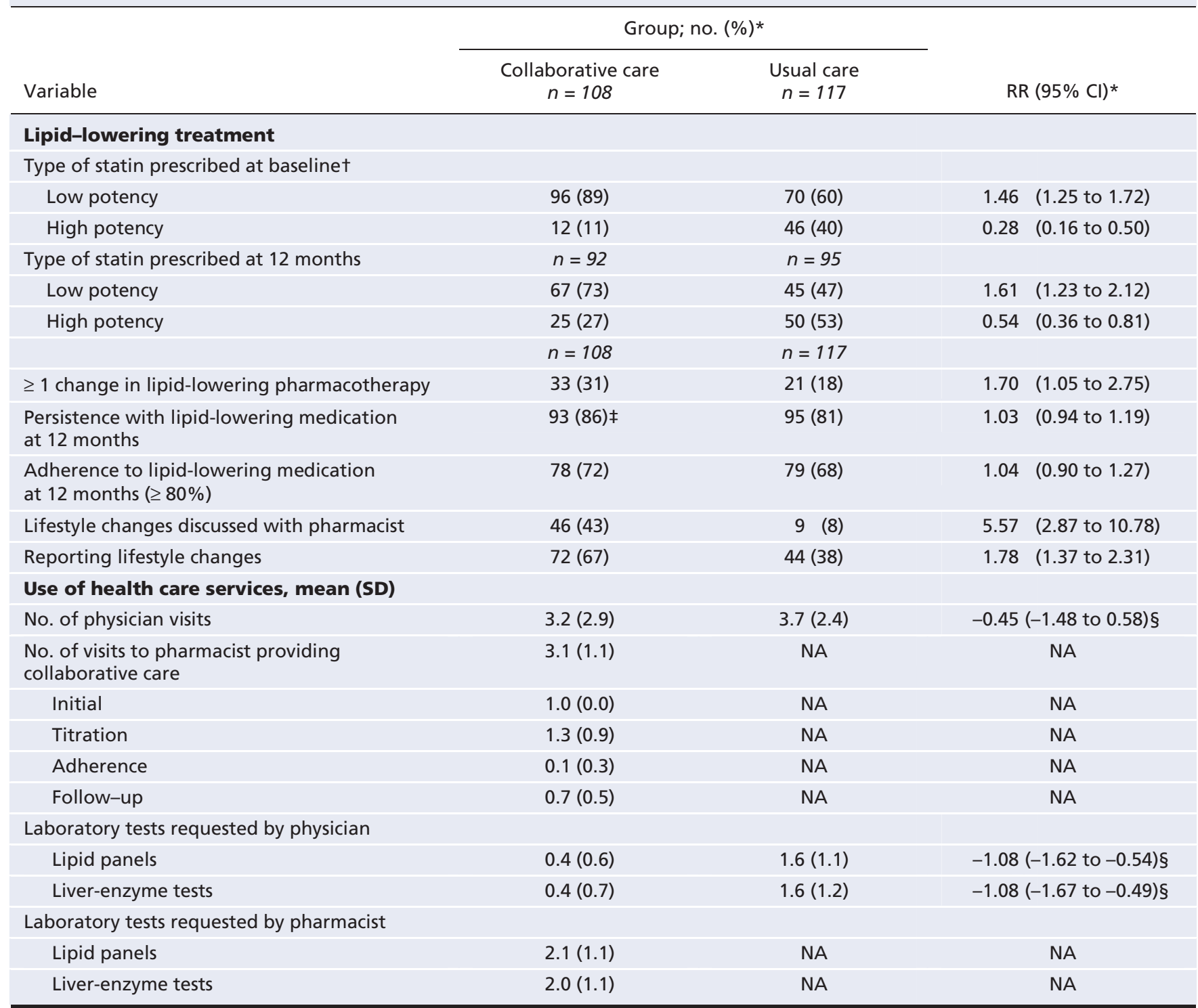

Note: $\mathrm{Cl}=$ confidence interval, $\mathrm{NA}=$ not applicable, $\mathrm{RR}=$ relative risk, $\mathrm{SD}=$ standard deviation

*Unless indicated otherwise.

tInformation on the statin in use at baseline was unavailable for one patient in the usual care group.

¥At 12 months, 93 patients in the collaborative care group were taking a lipid-lowering medication, including the 92 patients who were taking a statin.

§Between-group difference $(95 \% \mathrm{Cl})$. 
collaborative care had 3.1 pharmacist visits, equivalent to 64 (SD 18) minutes of consultation, over a mean of 6.6 months (SD 0.3). Pharmacists requested a mean of 2.1 (SD 1.1) lipid panels and 2.0 (SD 1.1) liver-enzyme tests for these patients.

\section{Adverse events}

Two patients receiving usual care died of cancer. Sixteen patients reported stopping their statin treatment because of adverse events: muscular pain (six patients in the collaborative care group, four in the usual care group); effects on the central nervous system, specifically insomnia or headache (one in the collaborative care group, three in the usual care group); or gastrointestinal effects (one in the collaborative care group, one in the usual care group).

\section{Interpretation}

In a collaborative primary care model in which community pharmacists were responsible for titrating lipid-lowering medication, patients made more visits to health care professionals than patients receiving usual care, underwent more laboratory tests, were more likely to have their lipid-lowering treatment modified and were more likely to report making lifestyle changes. However, these differences did not translate into a significant clinical effect on lipid control. At 12 months, after adjustment for potential confounders, collaborative care was not associated with a significant incremental reduction in LDL cholesterol $(-0.05$ $\mathrm{mmol} / \mathrm{L}, 95 \% \mathrm{CI}-0.3$ to 0.2 ), and the probability of reaching target lipid levels was only slightly higher among patients receiving collaborative care (RR 1.16, 95\% CI 1.01 to 1.34 ).

The collaborative care intervention was described in a detailed treatment protocol and was supported by clinical tools. Almost all (58 [97\%]) of the 60 pharmacists assigned to the collaborative care group attended a training workshop. The number of laboratory tests, visits to the pharmacist and changes in pharmacotherapy indicated that pharmacists were applying the treatment protocol as specified. As a result, $81 \%$ of the patients receiving collaborative care reached their targets, with a mean reduction in LDL cholesterol of $1.1 \mathrm{mmol} / \mathrm{L}(31 \%)$. This compares favourably with the outcomes of the Second Study of Cardiovascular Risk Intervention by Pharmacists, ${ }^{20}$ in which community pharmacists provided counselling, point-ofcare cholesterol testing and referral to a physician. After six months, $27 \%$ of the patients had reached their targets, with a reduction in LDL cholesterol of $15 \%$. In studies of specialized clinics where pharmacists monitored pharmacotherapy and adjusted dosages, the proportion of patients reaching their target lipid levels ranged from $39.5 \%$ to $79.1 \% .^{21-29} \mathrm{~A}$ meta-analy$\mathrm{sis}^{30}$ reported a reduction in LDL cholesterol of $0.84 \mathrm{mmol} / \mathrm{L}$. All of these results suggest that a collaborative care model could be implemented in primary care with similar results. However, this study provided no evidence of a significant clinical impact on lipid control relative to usual care.

\section{Limitations}

The lack of clinical effect may have been due to the recruitment of patients with modestly elevated LDL cholesterol. In both groups, the observed reduction in LDL cholesterol (-1.1 $\mathrm{mmol} / \mathrm{L}$ in the collaborative care group, $-0.9 \mathrm{mmol} / \mathrm{L}$ in the usual care group $)$ exceeded the treatment gap $(0.8 \mathrm{mmol} / \mathrm{L}$ in the collaborative care group, $0.7 \mathrm{mmol} / \mathrm{L}$ in the usual care group), although only a minority of patients underwent dosage titration during the study (31\% of patients in the collaborative care group, $18 \%$ of those in the usual care group). Furthermore, we observed important baseline differences in prescription patterns between the groups. High-potency statins were more often prescribed for patients receiving usual care $(40 \%$ v. $11 \%)$. The randomization of a small number of clusters might have led to confounding, whereas the recruitment of patients after randomization might have induced selection bias, which would explain the between-group differences observed at baseline. Finally, only $10 \%$ of the clusters approached were eligible and agreed to participate, which might have decreased the external validity.

\section{Conclusions}

Collaborative primary care is feasible for the management of dyslipidemia, but it does not necessarily have any effect on patients' outcomes. In future studies, the long-term benefits of this approach should be evaluated for patients at high risk of coronary artery disease with target LDL cholesterol below 2 $\mathrm{mmol} / \mathrm{L}$, who are likely to require dosage adjustments.

\section{This article was peer reviewed.}

Competing interests: Marie-Thérèse Lussier is the principal investigator for a research project funded by AstraZeneca Canada. She has received educational grants for adaptation and translation of patient communication papers from Merck, AstraZeneca and Sanofi. She received sponsorship from AstraZeneca to attend the European Association for Communication in Health Care $(\mathrm{EACH})$ meeting in September 2008. None declared for all other authors.

Contributors: Lyne Lalonde, Julie Villeneuve, Jacques Genest, Lucie Blais, Marie-Claude Vanier, Diane Lamarre, Marie-Thérèse Lussier, Sylvie Perreault and Eveline Hudon contributed substantially to the conception and design of the study protocol; Julie Villeneuve and Lyne Lalonde contributed to the acquisition of data; and Julie Villeneuve, Lyne Lalonde, Lucie Blais, Djamal Berbiche and Marc Fredette were responsible for the data analysis. As principal investigator, Lyne Lalonde was responsible for writing the study protocol and this paper, as well as supervising the conduct of the study and the statistical analyses. All of the authors critically revised the article and gave final approval for the version submitted.

Acknowledgements: The authors thank Josée Robillard MSc (research assistant), Caroline Le Pottier BPharm (research assistant), Marie-Noël Lachambre BSc (research nurse), Nathalie Caron (research technician) and Chantal Legris (administrative assistant), all of whom made invaluable contributions to the collection of data. A special thank-you to all of the pharmacists, physicians and patients who generously participated in this trial.

Funding: This research was funded by a grant from the Canadian Institutes of Health Research (grant number 200409MCT-133732-RCT) and unrestricted research grants from AstraZeneca Canada Inc., Merck Frosst Canada Ltd. and Pfizer Canada Inc. Research scholars Lyne Lalonde, Lucie Blais and Sylvie Perreault received financial support from the Fonds de la recherche en santé du Québec.

\section{REFERENCES}

1. Gould AL, Davies GM, Alemao E, et al. Cholesterol reduction yields clinical benefits: meta-analysis including recent trials. Clin Ther 2007;29:778-94.

2. Avorn J, Monette J, Lacour A, et al. Persistence of use of lipid-lowering medications. A cross-national study. JAMA 1998;279:1458-62.

3. Perreault S, Blais L, Lamarre D, et al. Persistence and determinants of statin therapy among middle-aged patients for primary and secondary prevention. Br J Clin Pharmacol 2005;59:564-73. 
4. Bourgault C, Davignon J, Fodor G, et al. Statin therapy in Canadian patients with hypercholesterolemia: the Canadian Lipid Study — Observational (CALIPSO) Can J Cardiol 2005;21:1187-93.

5. Farahani P, Levine M. Goal attainment for multiple cardiovascular risk factors in community-based clinical practice (a Canadian experience). J Eval Clin Pract 2009;15:212-6.

6. Farris KB, Fernandez-Llimos F, Benrimoj SI. Pharmaceutical care in community pharmacies: practice and research from around the world. Ann Pharmacother 2005;39:1539-41.

7. Alliance for Pharmaceutical Care. Collaborative drug therapy management: coordinated approach to patient care. Available: www.pswi.org/professional /patient/drugtherapy.pdf (accessed 2009 Feb. 12).

8. Genest J, Frohlich J, Fodor G, et al. Recommendations for the management of dyslipidemia and the prevention of cardiovascular disease: summary of the 2003 update. CMAJ 2003;169:921-4.

9. Grumbach $\mathrm{K}$, Bodenheimer $\mathrm{T}$. Can health care teams improve primary care practice? JAMA 2004;291:1246-51.

10. Villeneuve J, Lamarre D, Vanier MC, et al. How to help patients manage their dyslipidemia: a primary care physician-pharmacist team intervention. Can Pharm 2007;140:300-5.

11. TEAM study - clinical and communication tools. Laval (QC): Centre de santé et de services sociaux de Laval, Equipe de recherche en soins de première ligne; 2008. Available: www.recherchepl.ca/autres-productions-scientifiques.php\#cat3 (accessed 2009 July 13).

12. Lalonde L, O'Connor AM, Drake E, et al. Development and pre-testing of a patient decision aid to assist pharmaceutical care in the prevention of cardiovascular disease. Pharmacotherapy 2004;24:909-22.

13. Villeneuve J, Lamarre D, Lussier MT, et al. Physician-pharmacist collaborative care for dyslipidemia patients: knowledge and skills of community pharmacists. $J$ Contin Educ Health Prof 2009;29:201-8.

14. Jones PH, Davidson MH, Stein EA, et al. Comparison of the efficacy and safety of rosuvastatin versus atorvastatin, simvastatin, and pravastatin across doses (STELLAR* Trial). Am J Cardiol 2003;92:152-60.

15. Blasetto JW, Stein EA, Brown WV, et al. Efficacy of rosuvastatin compared with other statins at selected starting doses in hypercholesterolemic patients and in special population groups. Am J Cardiol 2003;91(5A):3C-10C

16. Jones P, Kafonek S, Laurora I, et al. Comparative dose efficacy study of atorvastatin versus simvastatin, pravastatin, lovastatin, and fluvastatin in patients with hypercholesterolemia (the CURVES Study). Am J Cardiol 1998;81:582-7.

17. Zou G. A modified Poisson regression approach to prospective studies with binary data. Am J Epidemiol 2004;159:702-6.

18. Steiner JF, Prochazka AV. The assessment of refill compliance using pharmacy records: methods, validity, and applications. J Clin Epidemiol 1997;50:105-16.

19. McPherson R, Frohlich J, Fodor G, et al. Canadian Cardiovascular Society position statement - recommendations for the diagnosis and treatment of dyslipidemia an prevention of cardiovascular disease. Can J Cardiol 2006;22:913-27.

20. Tsuyuki RT, Olson KL, Dubyk AM, et al. Effect of community pharmacist intervention on cholesterol levels in patients at high risk of cardiovascular events: the Second Study of Cardiovascular Risk Intervention by Pharmacists (SCRIP-plus). Am J Med 2004;116:130-3.

21. Ellis SL, Carter BL, Malone DC, et al. Clinical and economic impact of ambulatory care clinical pharmacists in management of dyslipidemia in older adults: the IMPROVE study. Impact of Managed Pharmaceutical care on Resource utilization and Outcomes in VEterans affairs medical centers. Pharmacotherapy 2000;20:1508-16.

22. Bozovich M, Rubino CM, Edmunds J. Effect of a clinical pharmacist-managed lipid clinic on achieving National Cholesterol Education Program low-density lipoprotein goals. Pharmacotherapy 2000;20:1375-83.

23. Geber J, Parra D, Beckey NP, et al. Optimizing drug therapy in patients with cardiovascular disease: the impact of pharmacist-managed pharmacotherapy clinics in a primary care setting. Pharmacotherapy 2002;22:738-47.

24. Cording MA, Engelbrecht-Zadvorny EB, Pettit BJ, et al. Development of a phar macist-managed lipid clinic. Ann Pharmacother 2002;36:892-904.

25. Till LT, Voris JC, Horst JB. Assessment of clinical pharmacist management of lipidlowering therapy in a primary care setting. J Manag Care Pharm 2003;9:269-73.

26. Straka RJ, Taheri R, Cooper SL, et al. Achieving cholesterol target in a managed care organization (ACTION) trial. Pharmacotherapy 2005;25:360-71.

27. Mazzolini TA, Irons BK, Schell EC, et al. Lipid levels and use of lipid-lowering drugs for patients in pharmacist-managed lipid clinics versus usual care in 2 VA Medical Centers. J Manag Care Pharm 2005;11:763-71.

28. Rehring TF, Stolcpart RS, Sandhoff BG, et al. Effect of a clinical pharmacy service on lipid control in patients with peripheral arterial disease. J Vasc Surg 2006;43: 105-10.

29. O'Donnell DC, Chen NT, Piziak VK. Goal attainment and maintenance of serum cholesterol level in a pharmacist-coordinated lipid clinic. Am J Health Syst Pharm 2001; $\$ 8: 325-30$.

30. Machado M, Nassor N, Bajcar JM, et al. Sensitivity of patient outcomes to pharmacist interventions. Part III: systematic review and meta-analysis in hyperlipidemia management. Ann Pharmacother 2008;42:1195-207.

Correspondence to: Dr. Lyne Lalonde, Research Team in Primary Care, Centre de santé et de services sociaux de Laval, Hôpital de la Cité-de-la-Santé, 1755 René-Laennec Blvd., Rm. D-S080, Laval QC H7M 3L9; lyne.lalonde@umontreal.ca

\section{HYDROMORPH Contin'qi2h}

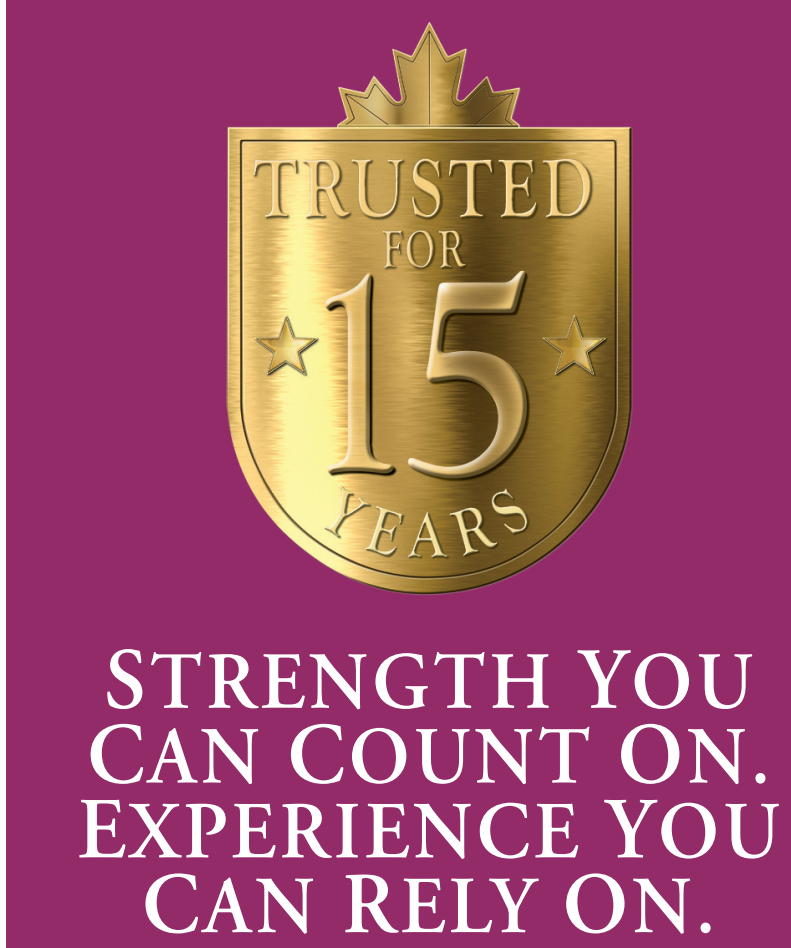

Hydromorph Contin ${ }^{\oplus}$ is indicated for the relief of severe chronic pain requiring the prolonged use of an oral opioid preparation.

Side effects are similar to other opioid analgesics. The most frequently observed are asthenic conditions, confusion, constipation, dizziness, lightheadedness, nausea, sedation, sweating and vomiting. Dosage limitations may be imposed by adverse effect. If they occur, please refer to prescribing information.

Warning: Opioid analgesics should be prescribed and handled with a high degree of caution appropriate to the use of a drug with strong abuse potential. Patients should be cautioned not to consume alcohol while taking Hydromorph Contin ${ }^{\circledR}$, as it may increase the chance of experiencing dangerous side effects. Hydromorph Contin ${ }^{\circledR} 18 \mathrm{mg}$ capsules and higher are for use in opioid tolerant patients only. There is a potential for fatal respiratory depression in patients not previously exposed to similar equianalgesic doses of an opioid analgesic.

Hydromorph Contin ${ }^{\circledast}$ capsules or capsule beads should not be chewed, crushed or dissolved since this can lead to rapid release and absorption of a potentially fatal dose of hydromorphone. Product monograph available on request.

Hydromorph Contin ${ }^{\circledR}$ capsule beads may be sprinkled on cold, soft food.

\section{'HYDROMORPH Contin'q12h \\ Controlled release hydromorphone capsules}

A trusted first choice for severe chronic pain

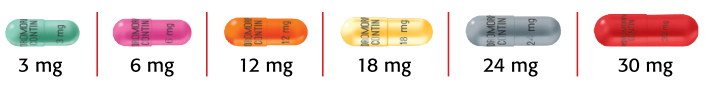

Initiation at $3 \mathrm{mg} \mathrm{q12h}$. Titration every 48 hours to satisfactory pain relief with acceptable side effects - increase first dose by $3 \mathrm{mg}$ to $6 \mathrm{mg} \mathrm{q} 12 \mathrm{~h}$, then in $6 \mathrm{mg}$ increments from $12 \mathrm{mg}$ to 30 $\mathrm{mg} \mathrm{q} 12 \mathrm{~h}$ - with no ceiling dose
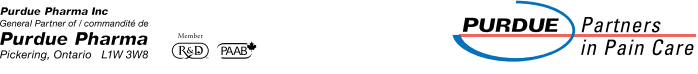

See prescribing summary on page 504 